E. C. ASHBY ET $A L$.: SEVERE GASTROINTESTINAL HAEMORRHAGE

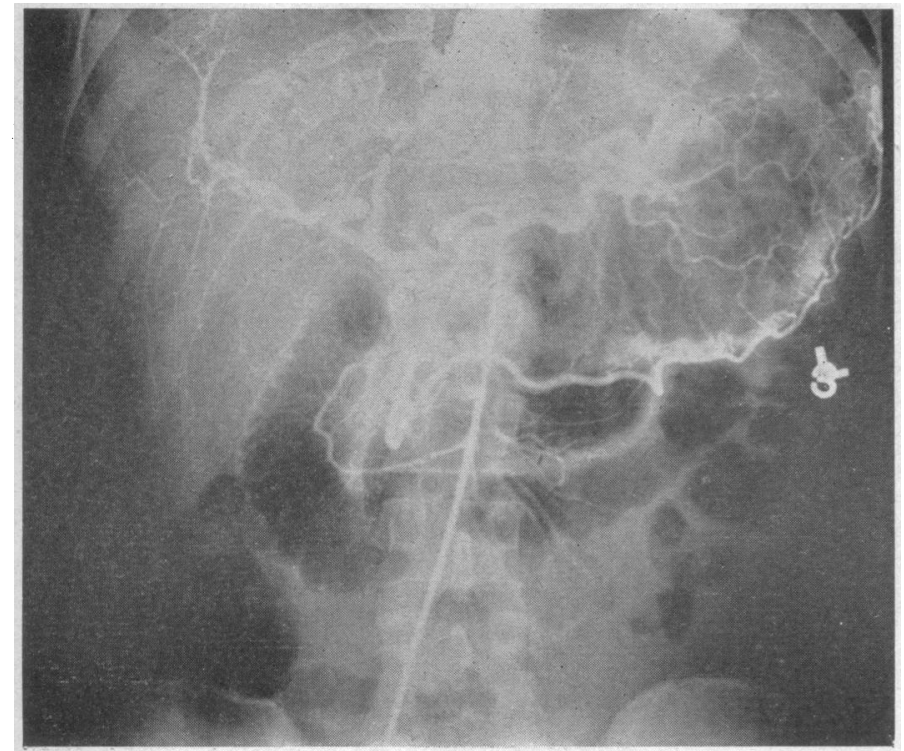

FIG. 1

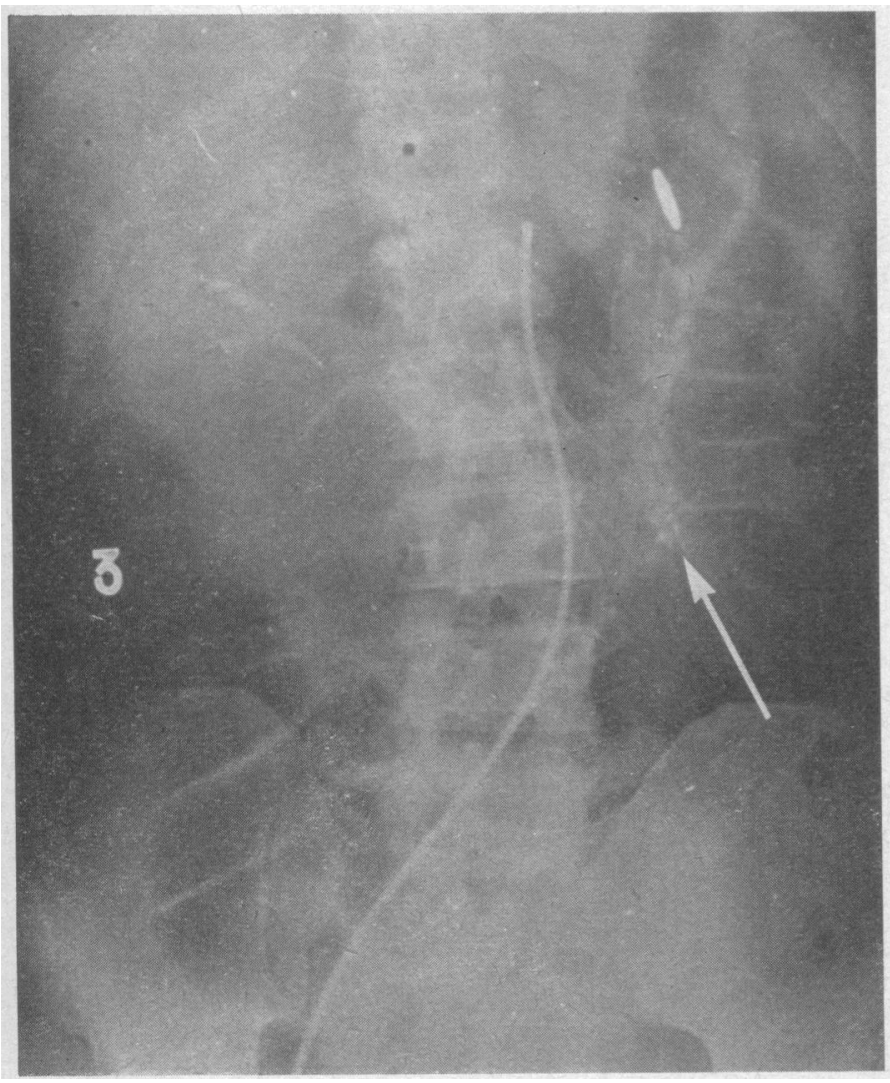

Fig. 3

FIG. 1.-Case 1. Coeliac arteriography-arterial phase. The arteries in the stomach wall are greatly increased in size and the mucosa is abnormally thick.

FIG. 2.-Case 1. Coeliac arteriography-late arterial phase. There is early venous filling.

Fig. 3.-Case 2. Superior mesenteric arteriography-capillary phase, showing early filling of veins in haemangioma (arrow).

Fig. 4.-Case 2. The mucosal lesion (arrow).

FIG. 5.-Case 2. Microscopical appearances of the haemangioma.

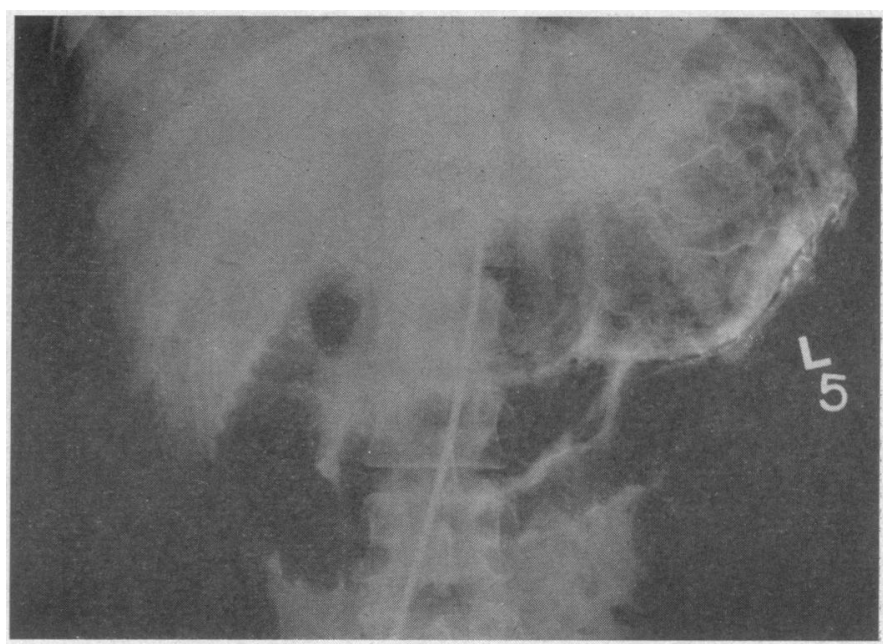

FIG. 2

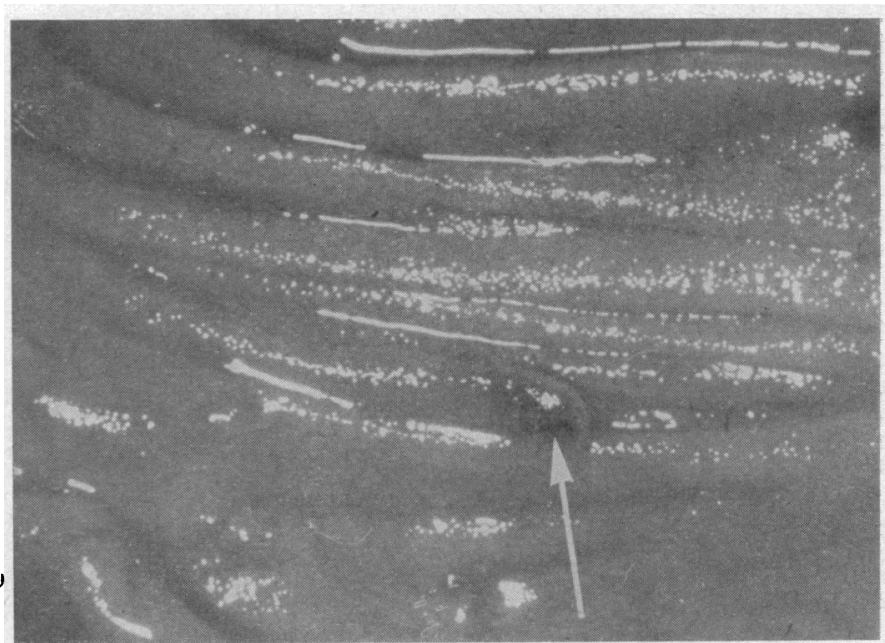

FIG. 4

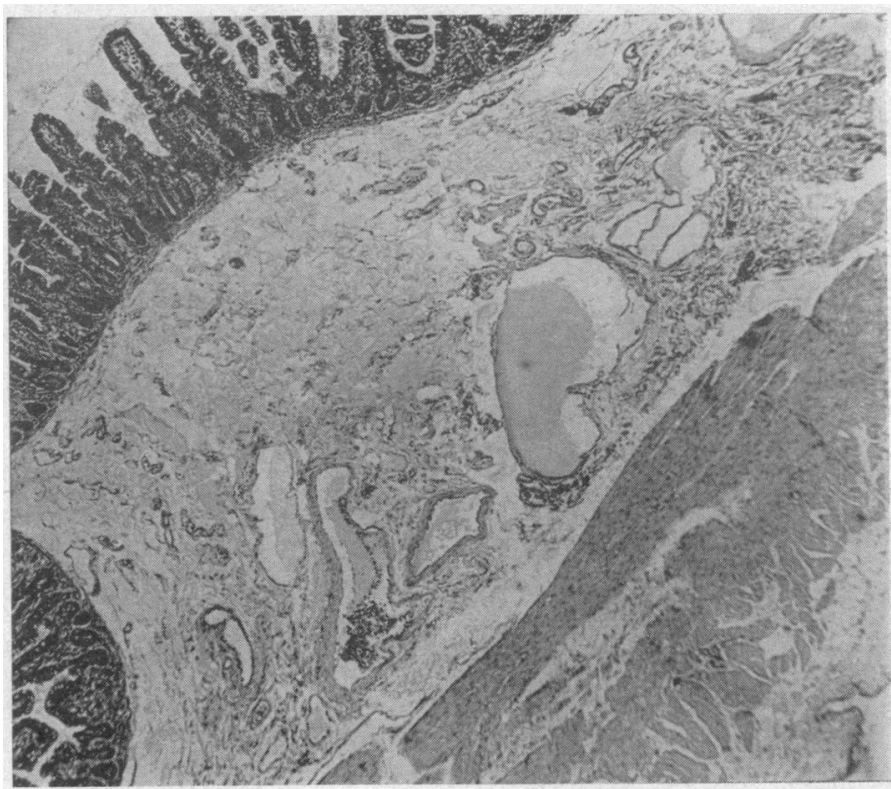

FIG. 5 
been described to make possible this distinction, but none is reliable (Trapnell, 1967). Some of the radiological features in this series are given in Table II. According to Shanks (1958), any gastric ulcer with a diameter of more than $2.5 \mathrm{~cm}$. should be regarded as being malignant until proved otherwise. However, Jennings and Richardson (1954) stress that giant ulcers are often benign, and Kemp Harper and Green (1961) found that an ulcer of such dimensions is almost as frequently benign as malignant. Three of the present cases had ulcers with a diameter of $4.5-5 \mathrm{~cm}$.

The site of a particular gastric ulcer is an unreliable guide in distinguishing between those that are benign and those that are malignant, but Shanks (1958) found that malignant ulcers occurred most commonly on the lesser curve near the pylorus. Prepyloric and pyloric ulcers are regarded by most radiologists as at least potentially malignant. Six of the ulcers in our series were in this position. One of these was large and shallow with rolled edges, and did not project from the stomach outline (Case 3, Fig. 1). Projection from the stomach outline is probably the most reliable single radiological feature of a benign gastric ulcer (Trapnell, 1967). It is notable that all but one of our cases (No. 3) did project in this way.

We wish to thank Professor M. D. Milne for permission to report Case 5, and Dr. G. E. Hosking for Cases 6, 9, and 10. In addition, we are grateful to Dr. G. D. Hadley for gastric photography in Case 3.

\section{REFERENCES}

Baragar, F. D., and Duthie, J. J. R. (1960). Brit. med. 7., 1, 1106.

Boardman, P. L., and Hart, F. D. (1967). Ann. rheum. Dis., 26, 127.

Gibberd, F. B. (1966). Acta rheum. scand., 12, 112.

Harper, R. B. K, and Green, B. (1961). Clin. Radiol., 12, 95.

Hart, F. D. (1965). Brit. med. f., 2, 1000.

Hart, F. D. (1965). Brit. med. J., 2, 1000. Lancet, 2, 343.

Jennings, D., and Richardson, J. E. (1954). Lancet, 2, 343 .

33, 25.
Lockie, L. M., and Norcross, B. M. (1966). In Arthritis and Allied Conditions, 7 th ed., edited by J. L. Hollander, p. 345 . London.

Lövgren, O., and Allander, E. (1964). Brit. med. f., 1, 118.

Shanks, S. C. (1958). In A Textbook of X-ray Diagnosis, 3rd ed., vol. 3, edited by S. C. Shanks and P. Kerley. London.

Short, C. L., Bauer, W., and Reynolds, W. E. (1957). Rheumatoid Arthritis. Cambridge, Massachusetts.

Trapnell, D. H. (1967). Principles of X-ray Diagnosis, p. 102. London.

\title{
Severe Gastrointestinal Haemorrhage: Haemangiomata Demonstrated by Selective Visceral Arteriography
}

\author{
E. C. ASHBY,* M.CHIR., F.R.C.S. ; T. J. MOTT, † F.R.C.S. ; F. STARER, $\ddagger$ M.R.C.P.ED., F.F.R.
}

[With Special Plate Facing Page 733]

\begin{abstract}
Cummary : Selective visceral arteriography was found to be invaluable in the management of two cases of severe gastrointestinal haemorrhage associated with cavernous haemangiomata (a large gastric haemangioma and a small jejunal haemangioma). It is suggested that arteriography may be indicated in cases where a previous laparotomy has not shown the cause of bleeding, when the patient's general condition precludes a prolonged operation, and when superficial haemangiomata are found.
\end{abstract}

\section{Introduction}

Conventional clinical methods often fail to show a cause for gastrointestinal haemorrhage. The failure rate has been of the order of $15-33 \%$ in some large series (Birke and Engstedt, 1956 ; Jones et al., 1959 ; Berkowitz, 1963). At operation the source of bleeding often remains obscure (Retzlaff et al., 1961).

Gastrointestinal haemorrhage of obscure origin may be due to haemangiomata much more frequently than is recognized, since these are difficult to find at operation. For instance, Rutter (1956) reported a case in which bleeding from the ascending colon was located at the third operation; only during pathological examination of the removed colon was a haemangioma found. It has been argued that the not infrequent success of "blind" partial gastrectomy may sometimes be due to removal of small unrecognized haemangiomata (Bongiovi and Duffy, 1967).

\footnotetext{
* Senior Surgical Registrar.

† Formerly Surgical Registrar

$\ddagger$ Consultant Radiologist.

Westminster Hospital, London SW.1
}

We report below two cases in which angiomata gave rise to severe intermittent gastrointestinal haemorrhage. In these cases selective visceral arteriography was an invaluable diagnostic method.

\section{Case 1}

A 28-year-old man was admitted to hospital in August 1963 with severe haematemesis and melaena. For 10 years he had had vague dyspepsia for which no cause had been found at a bariummeal examination eight years previously. At the age of 5 years he had been investigated at another hospital for profuse vomiting and some haematemesis which had settled spontaneously.

On examination he was pale and shocked, and the only other physical sign of note was a capillary haemangioma measuring 5 by $2.5 \mathrm{~cm}$. on his face. A Gastrografin contrast study showed no abnormality.

At gastroscopy a small depressed area was seen on the posterior aspect of the lesser curve of the stomach, which was covered by mucus streaked with blood, and he was thought to have haemorrhagic gastritis.

He was readmitted in October 1964 with melaena of one day's duration and exacerbation of dyspepsia for three weeks. As he continued to bleed it was decided to perform a laparotomy. The site of bleeding was found to be an area of greatly thickened angiomatous mucosa high on the lesser curve, and the gastric mucosa elsewhere tended to be hypertrophic and friable. A Billroth I type of gastrectomy was carried out, the lesser curve being resected right up to the cardia. Histology showed a cavernous haemangioma of hamartomatous nature.

He remained well until his readmission with a further haemorrhage in November 1966. Coeliac and superior mesenteric arteriography then showed grossly hypertrophied left gastric and gastroduodenal arteries giving rise to numerous large gastric branches ending in arteriovenous fistulae with early filling of drainage veins (Special Plate, Fig. 1). The gastric mucosa stained heavily with contrast 
and was grossly thickened (Special Plate, Fig. 2). Virtually all of the stomach remnant and the first part of the duodenum were seen to be involved. A subsequent barium examination showed large mucosal folds in the upper part of the stomach. In December 1966 a high Polya type of partial gastrectomy was carried out, since when no further bleeding has occurred.

In this case arteriography was of value in showing the full extent of the malformation.

\section{Case 2}

A 41-year-old man was admitted to hospital in November 1967 with a history of passing about 3 pints ( 1.7 litres) of red blood per rectum in the previous nine hours. $\mathrm{He}$ also complained of slight left iliac fossa pain. There had been an uninvestigated episode of rectal bleeding three years previously.

On examination he was very pale and shocked. Apart from slight left iliac fossa tenderness there were no other abnormal physical signs and no cutaneous or mucosal haemangiomata were seen.

Barium meal, follow-through, and enema examinations, sigmoidoscopy, and bleeding and clotting factors were all normal. The overt bleeding settled but the stools remained positive to occult blood testing for 10 days.

At subsequent operation no cause for the bleeding was found, in spite of endoscopic examination of the whole large bowel and terminal ileum as well as inspection of the more proximal part of the digestive tract.

Two days later, when he was still suffering from postoperative ileus, further rectal bleeding occurred. Selective superior mesenteric arteriography showed a small jejunal haemangioma (Special Plate, Fig. 3). Three days after this, when his general condition had improved, a second operation was carried out.

Again no abnormality was noted in the jejunum or its mesentery, in spite of transillumination as well as inspection and palpation, and firm handling failed to provoke any detectable bleeding. An attempt was made to locate the haemangioma by reference to the arterial arcades, and the bowel was opened at the anticipated site about $50 \mathrm{~cm}$. from the duodenojejunal flexure, Endoscopic examination of the proximal $100 \mathrm{~cm}$. of jejunum showed no abnormality. Opposite a second enterostomy about $150 \mathrm{~cm}$. from the duodenojejunal flexure a small laceration with a raised tag of bluish mucosa was found (Special Plate, Fig. 4). At this point $15 \mathrm{~cm}$. of jejunum was resected. He made a good recovery from the operation and since then no further bleeding has occurred.

Histological examination showed a very small area of cavernous haemangioma confined to the submucous layer (Special Plate, Fig. 5).

Without arteriography it is unlikely that the approximate site and the cause of the bleeding could have been located at the second operation.

\section{Discussion}

\section{Features of Alimentary Haemangiomata}

The literature on alimentary haemangiomata includes good reviews by Gentry et al. (1949), Shepherd (1953), and Rissier (1960).

Gentry et al. (1949) found 106 cases in 1,400,000 Mayo Clinic case records, but almost half of these were discovered at necropsy. The stomach accounted for $12 \%$ and the small intestine for $45 \%$. The majority were benign, and it is possible that some of the lesions described as malignant were in fact multiple hamartomata. Rissier certainly favoured the view that most intestinal haemangiomata were hamartomata.

According to Rissier any classification of haemangiomata was of limited value because of overlap of various types, but the most popular was the Obendorfer-Kaijser classification:

I. Multiple phlebectasias.

II. Cavernous haemangiomata: (A) diffusely infiltratirg; (B) polypoid.

III. Capillary haemangiomata (simplex).

IV. Special group: angiomatosis with gastrointestinal localization-for example, Osler-Rendu-Weber syndrome.
Clinical features of a large collected series were well tabulated by Rissier (1960). The diagnosis was rarely made preoperatively but might be suggested by the presence of cutaneous or mucosal haemangiomata, or by groups of phleboliths outside the pelvic area on plain $x$-ray films. Bleeding could begin at any age, with the peak incidence at 20 to 50 years. The average length of history of intermittent bleeding was 12 years, but had been recorded to be as long as 40 years. Multiple lesions were twice as common as single. Males were affected twice as often as females, a reversal of the usual ratio in cutaneous haemangiomata.

Shiffman and Rappaport (1967) suggested that delay in presentation until later life might be due to loss of structural support for the vessels because of degeneration of the connective tissue stroma.

\section{Arteriography in Obscure Haemorrhage}

Percutaneous selective visceral arteriography has been found to have a high technical success rate with the coeliac and superior mesenteric arteries (Nebesar et al., 1964 ; Baum et al., 1967) and with the inferior mesenteric artery in other than elderly subjects (Ström and Winberg, 1962). This is confirmed by our own experience.

In general the technique is safe, need not unduly delay surgery, and by locating the source of bleeding may reduce intra-abdominal manipulations and operation time. Caution is necessary when the circulation is slowed by shock or cardiac failure because of a risk of femoral artery thrombosis in those circumstances (Reuter and Bookstein, 1968).

With positive information gained in 18 out of 21 cases, Baum et al. (1967) thought that results justified its wider use as a preoperative investigation. During active bleeding diagnosis depends on the recognition of contrast escape from the vessel into the lumen of the bowel. Experimental work (Baum et al., 1965) suggested that pooling of dye at the site of haemorrhage could be visualized if the bleeding rate was greater than $0.5 \mathrm{ml}$. per minute. When bleeding had ceased the source might be indicated by an abnormal vascular pattern due to a primary vascular abnormality, a tumour, or an inflammatory lesion.

Reuter and Bookstein (1968) demonstrated the site of bleeding in 11 out of 16 actively bleeding cases and in 9 out of 13 chronic intermittently bleeding cases, four of the latter being vascular lesions. They suggested that if the patient was bleeding actively and there was no clinical indication of the site, then arteriography should be the initial radiological procedure. Ill patients often tolerated barium studies less well than arteriography, the presence of blood clots might make interpretation difficult, and residual barium might, by obscuring the field, preclude arteriography for several days. Furthermore, evidence suggesting the presence of oesophageal varices demonstrable by arteriography but not necessarily by barium studies might prevent a meddlesome operation. With chronic intermittent bleeding barium studies would be done first, followed by arteriography if these showed no lesion.

It is debatable whether preoperative arteriography should be done routinely in cases of gastrointestinal haemorrhage of obscure origin. The added risks of arteriography must be weighed against the risks of an unnecessarily prolonged or fruitless operation. In cases where a previous laparotomy has not shown the cause of bleeding (or the extent of the lesion), or where the general condition of the patient would make a prolonged operation hazardous, or where superficial haemangiomata are found, the balance of risks would certainly seem to favour arteriography.

Though this paper deals primarily with intestinal haemangiomata it should be added that an increasing number of other lesions causing alimentary bleeding are being reported as having been recognized by visceral angiography. 
Our own experience of selective visceral arteriography is at present limited. Further experience will be required to define its place in the investigation of gastrointestinal haemorrhage. In time more precise criteria of abnormalities on the arteriogram will be formulated. There is little doubt that selective visceral arteriography should be used more widely than is the practice in this country at present.

We wish to thank Dr. D. H. MacKenzie for the photomicrograph and the department of medical illustration, Westminster Hospital, for the other photographs. We are grateful to Mr. A. G. Rutter for allowing us to report Case 1, and to Mr. E. S. Lee and Professor M. D. Milne for allowing us to report Case 2. Case 2 was presented at the Clinical Section of the Royal Society of Medicine on 9 February 1968, and is reported by kind permission of the President of the Section.

\section{REFERENCES}

Baum, S., Nusbaum, M., Blakemore, W. S., and Finkelstein, A. K. (1965). Surgery, 58, 797.

Baum, S., Nusbaum, M., Clearfield, H. R., Kuroda, K., and Tumen, H. J. (1967). Arch. intern. Med., 119, 16.

Berkowitz, D. (1963). Amer. ₹ Gastroent., 40, 372.

Birke, G., and Engstedt, L. (1956). Gastroenterologia (Basel), 85, 97.

Bongiovi, J. J., and Duffy, J. L. (1967). Arch. Surg., 95, 93.

Gentry, R W, Dockerty, M. B. and Clagett, O. T. (1949). Int. Abstr. Surg., 88, 281.

Jones, F., A., Read, A. E., and Stubbe, J. L. (1959). Brit. med. F., 1, 1138 .

Nebesar, R. A., Pollard, J. J., Edmunds, L. H., and McKhann, C. F. (1964). Amer. 7. Roentgenol., 92, 1100.

Rctzlaff, J. A., Hagedorn, A. B., and Bartholomew, L. G. (1961). J. Amer. med. Ass., $177,104$.

Reuter, S. R., and Bookstein, J. J. (1968). Gastroenterology, 54, 876.

Rissier, H. L. (1960). Gastroenterologia (Basel), 93, 357.

Rutter, A. G. (1956). Lancet, 2, 1077.

Shepherd, J. (1953). Brit. 7. Surg. 40, 409.

Shiffman, M. A., and Rappaport, I. (1967). Arch. Surg., 94, 771.

Ström, B. G., and Winberg, T. (1962). Acta Radiol. (Stockh.), 57, 401.

\section{Function of Cadaver Renal Homografts in Relation to Age of Donor, Cause of Death, and Ischaemia Time}

The ideal donor (Nolan, 1967) of a cadaveric kidney for transplantation might be considered to be a person under the age of 45 years who has remained normotensive until a short time before death, who is free of transmissible infection and malignancy, and who dies in hospital after observation for a number of hours, during which time blood group and tissue type may be determined and urinary function assessed. The donor kidneys must then be removed within minutes and certainly within an hour of death. Such an ideal donor situation is not infrequent in the United States, where road traffic accidents and gunshot wounds are common and so provide adequate donors of this ideal type for the needs of renal transplantation. In Great Britain such ideal donors are the exception rather than the rule, and in this reported series (Calne et al., 1968) possibly only three donors out of 36 would have fulfilled all these criteria.

It is the purpose of this paper to study the function of the cadaveric kidneys with respect to the age of the donor, the cause of the donor's death, and the length of ischaemia time, in the hope that a case may be made for using what might be

\footnotetext{
- Honorary Senior Surgical Registrar, United Cambridge Hospitals. At present Lecturer in Surgery, Bristol University ; Consultant Surgeon, Southmead Hospital, Bristol.

† Senior Medical Registrar, Renal Unit, Addenbrooke's Hospital, Cambridge.

† Professor of Surgery, University of Cambridge.
}

termed "second-class donors" in order to satisfy the needs of renal transplantation in this country at the present time. It is admitted that the use of such donor kidneys is often followed by a period of acute tubular necrosis in the transplanted kidney, and this may make the early diagnosis of a threatened rejection extremely difficult.

\section{Materials and Methods}

Between 15 March 1966 and 1 April 196845 patients received 50 cadaveric renal transplants in Cambridge (Calne et al., 1968). Of these 45 recipients 13 have died and five further transplants have had to be removed for reasons of rejection, secondary haemorrhage, or venous thrombosis, all of which occurred within a four-month period following transplantation. It was therefore decided to assess the function of these cadaveric grafts at the end of this initial four-month period. This allows 26 grafts to be studied. The remaining six functioning grafts have been transplanted too recently for assessment at this period of time, three of these being second transplants and three first transplants. These 26 grafts have been obtained from 24 donors, 6 of whom died from cerebrovascular accidents, 2 from cerebral tumour, 8 from myocardial infarction, and 7 from road traffic accidents-2 kidneys being used on two occasions from this source-and a further graft was obtained from a patient dying of a pulmonary embolus.

\section{Results}

Fig. 1 shows the age of the donor plotted against the serum creatinine at the end of the four-month period following transplantation; it will be seen that the age of the donor really has no effect on the function of the graft at the end of this time, there being a random distribution of function irrespective of age. Table I shows the average serum creatinine at four months for each decade of the donor's age. Though the average for the over-60s is slightly higher at $1.9 \mathrm{mg} . / 100 \mathrm{ml}$., it is accounted for by a high serum creatinine $(3 \mathrm{mg} . / 100 \mathrm{ml}$.) in one patient. 